Saudi Journal of Oral and Dental Research

Abbreviated Key Title: Saudi J Oral Dent Res

ISSN 2518-1300 (Print) |ISSN 2518-1297 (Online)

Scholars Middle East Publishers, Dubai, United Arab Emirates

Journal homepage: http://scholarsmepub.com/sjodr/

Case Report

\title{
Laser Assisted Periodontal Therapy in Fibrous Dysplasia: A Treatment Option
}

\author{
Dr. Pragyan Mohanty, Dr. Sheela Kumar Gujjari ${ }^{*}$, Dr. Kunchok Dolma J \\ Department of Periodontology, JSS Dental College \& Hospital, JSS Academy of Higher Education \& Research, Mysuru-570015, Karnataka state, India
}

DOI: 1 10.36348/SJODR.2019.v04i12.008 $\quad$ | Received: 02.12.2019| Accepted: 09.12.2019| Published: 17.12 .2019

*Corresponding author: Dr. Sheela Kumar Gujjari

\section{Abstract}

Fibrous dysplasia is a developmental anomaly which involves the replacement of normal medullary space by abnormal fibrous osseous tissue in the affected bone. It has been reported to cause increased rate of bone resorption and bone refilling has been observed in $<50 \%$ of the defect. Patients with fibrous dysplasia can have periodontitis which is an immuno-inflammatory disease of the supporting tissues of the teeth with classic signs of periodontal pockets, recession or both. The goal of periodontal therapy is to thoroughly debride the periodontal pockets so as to prevent further damage to the surrounding bone and regenerate the lost periodontal structures. However, the treatment of periodontitis subjects with fibrous dysplasia is unpredictable and hence possesses a greater challenge for the clinician. This is a first report of its kind in the literature. This case report presents a 32year old patient with monostotic fibrous dysplasia having periodontitis and was treated by non surgical periodontal therapy which include scaling, root planning and curettage with soft tissue LASER as a non-invasive treatment modality. Laser assisted periodontal therapy resulted in resolution of the periodontal pocket as well as significant radiographic bone fill at the end of 6month recall visit.

Keywords: Fibrous dysplasia, Laser assisted periodontal therapy, periodontal regeneration.

Copyright @ 2019: This is an open-access article distributed under the terms of the Creative Commons Attribution license which permits unrestricted use, distribution, and reproduction in any medium for non-commercial use (NonCommercial, or CC-BY-NC) provided the original author and source are credited.

\section{INTRODUCTION}

Fibrous dysplasia (FD) is a relatively common, benign skeletal disorder typically encountered in adolescents and young adults. It was first described by Von Recklinghausen (1891) and the term was coined by Lichtenstein (1938) and Jaffe (1942) [1, 2].

Studies have linked the etiology of FD as a genetically based sporadic disease of the bone, occurring due to mutations in the gene (GNAS I) encoding for the $\alpha$-subunit of a signal transducing $G$ protein (Gs- $\alpha$ ) leading to increased c-AMP production which affects the proliferation and differentiation of preosteoblasts [3]. FD is postulated to occur as a result of a developmental failure in the remodeling of primitive bone to mature lamellar resulting in substantial loss of mechanical strength, leading to pain, deformity and pathologic fractures. ${ }^{4}$

FD can involve one bone (monostotic) or multiple bones (polyostotic) and may be linked with endocrinopathies. Majority of monostotic lesions are usually asymptomatic and discovered incidentally when radiographs of the involved region are made for other indications [4]. The most common radiographic characteristic of FD is a grayish "ground-glass" appearance with a thin cortex and without distinct borders. History, clinical examination and the classic radiographic presentation are often sufficient to substantiate the diagnosis of FD.

Periodontitis is an inflammatory disease of supporting tissues of teeth caused by specific microorganisms or groups of specific microorganisms, resulting in progressive destruction of the periodontal ligament and alveolar bone with periodontal pocket formation, gingival recession or both [5]. The main objective of the periodontal treatment is not only to stop the progression of the disease but also to regenerate the lost periodontal components. Many times, conventional surgical procedures are not welcomed by the patients due to the subjective apprehensions for pain, swelling and postoperative discomfort and its outcome in fibrous dysplasia is still unclear as it may deteriorate the periodontal bone loss.

LASER is a commonly accepted term for Light Amplification by Stimulated Emission of Radiation. Gregg and McCarthy first conceived and developed in 1990 and later proposed the use of laser to 
achieve bone regeneration $[6,7]$. It accelerates tissue repair and cell growth, bactericidal effect, aids in wound healing and reduces the formation of scar tissue. Several studies have provided significant evidence that photoactivation of lasers can cause photoeradication of the dental pathogens thereby reducing the probing depth [8-10]. Laser assisted periodontal therapy (LAPT) is one such method that brings revolutionary outcomes in periodontal treatment procedures. Therefore, LAPT was advocated as an exceptional alternative in this case.

However, in the literature there is no data that investigated the use of LASER therapy to treat or disinfect periodontal pockets in patients with fibrous dysplasia or any other bone dysplasia.

\section{CASE HISTORY}

A 32year old female reported to the department of periodontology with the chief complain of inflamed gingiva in the oral cavity. On clinical examination following findings were observed: probing depth of $6 \mathrm{~mm}-16$ (distal) with Grade I mobility (Fig-1), 44 and 45-Grade III Mobility and was advised for extraction. After extraction, a diffuse bicortical expansion (Fig 2a, 2b) was noted in the region of 44,45,46 alveolar ridge. On palpation, it was bony hard, non-compressible and non-fluctuant. Patient was advised orthopantomogram (OPG) for further evaluation (Fig-3) and incidental finding of a diffuse ground glass appearance with respect to $44,45,46$ was noted and suspected to be monostotic fibrous dysplasia. Monostotic fibrous dysplasia was confirmed with the help of the X-ray of hip and femur (Fig 4a, 4b) by the orthopedician. Routine hematological examination was carried out. Blood \& Biochemical investigations showed alkaline phosphates $87 \mathrm{IU} / \mathrm{l}$, Serum Calcium $9.8 \mathrm{mg} \%$ \& Serum Phosphorus $3.1 \mathrm{mg} \%$ which were within normal range.

Scaling and root planing was done using both the ultrasonic \& hand instruments. Patient was recalled after two weeks for check up and LAPT (curettage) was carried out in the periodontal pocket site (Fig 5a, 5b, 5c, $5 \mathrm{~d})$. The respective areas were anaesthetized with local infiltration of $2 \%$ lignocaine with adrenaline 1:80000 so that the pocket depths can be probed down to the level of intra-osseous defects (bone sounding). A soft tissue diode laser with 320um optic fiber tip was inserted parallel to the root surface, into the sulcus $1 \mathrm{~mm}$ above the base of the pocket using a continuous wave for approximately 15 seconds per site, to disinfect the pocket epithelium in a sweeping motion.

Then, an EMS ultrasonic scaler and curettes were used to remove the calcified plaque and calculus adherent to the root surface. Again LAPT was used with utmost precision to enhance the ability to form a fibrin clot, which secures the pocket from detritus matter and to disinfect \& close the mini-flap that was formed. The mini-flap was compressed against the tooth surface for 3-5mins for clot stabilization. Post surgical instructions was given including proper diet specifications along with oral hygiene instructions with an emphasis on continued periodontal maintenance. Patient was recalled at 3 days, 3 months and 6 months intervals and the periodontal pocket investigated showed significant improvement after LAPT (Fig 6a, 6b).

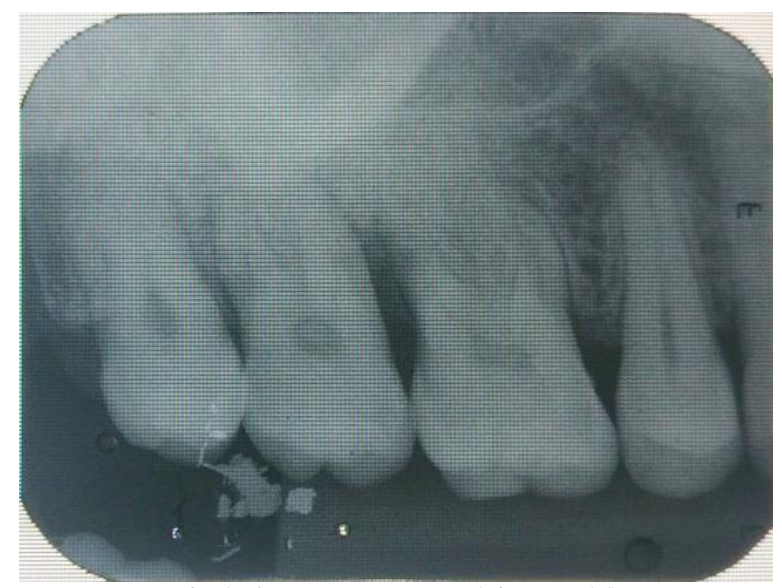

Fig-1: Angular Bone loss (distal to 16)

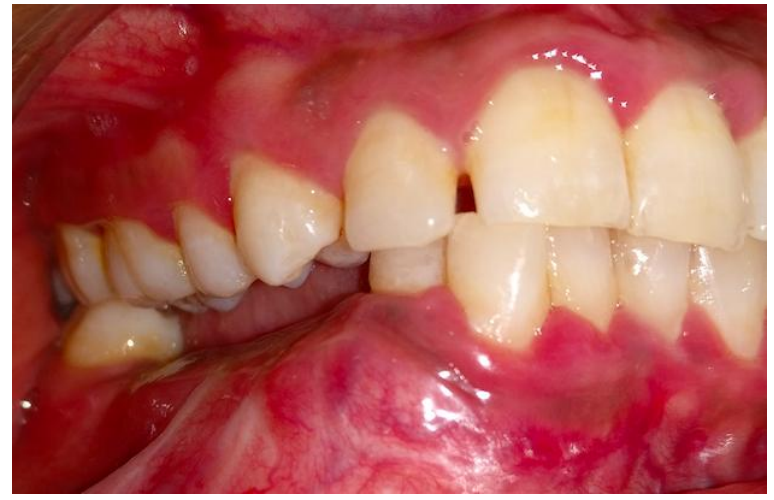

Fig-2a: Diffuse bicortical expansion (lateral view)

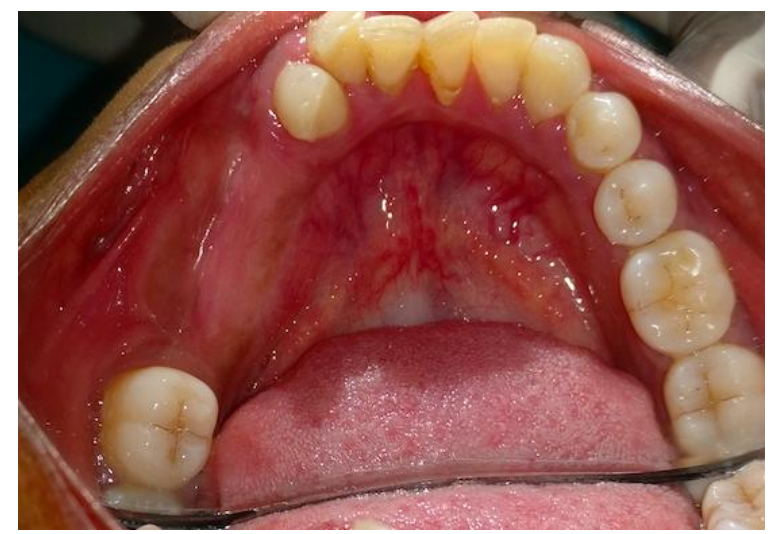

Fig-2b: Diffuse bicortical expansion (occlusal view) 


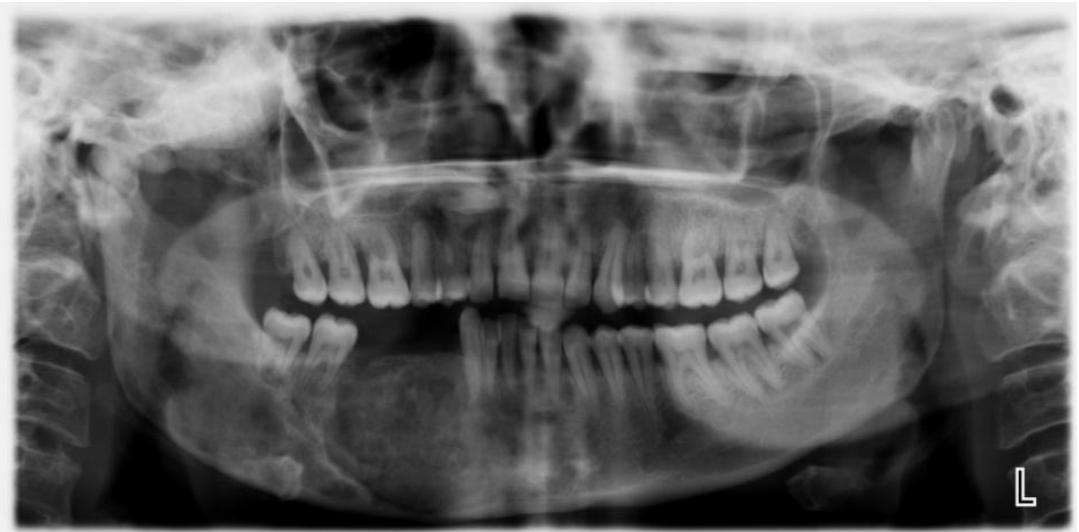

Fig-3: Orthopantomogram (OPG) revealing ground glass appearance in the region of $44,45 \& 46$

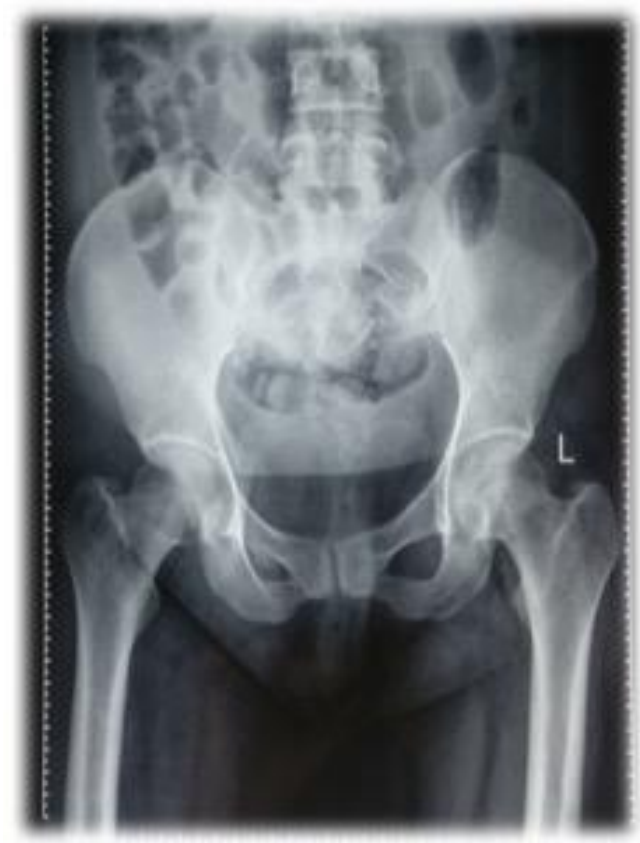

Fig-4a: X-ray of Hip

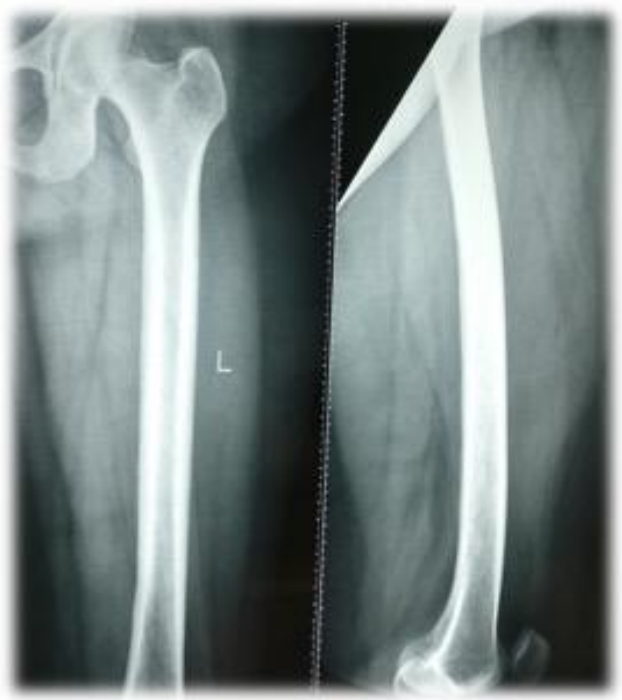

Fig-4b: X-ray of Femur

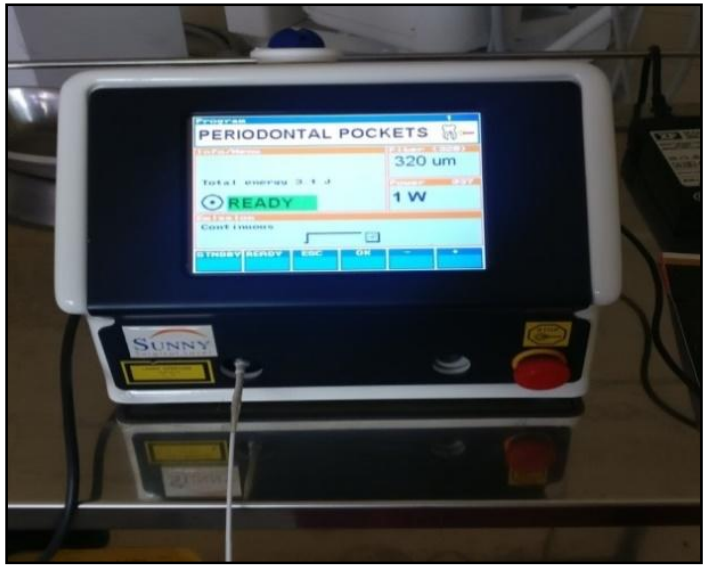

Fig-5a: Diode LASER Unit

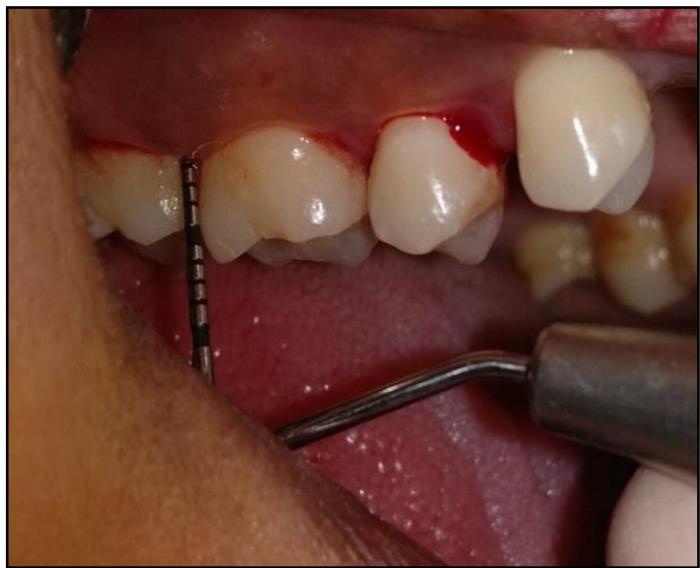

Fig-5b: 6mm probing depth (16) 


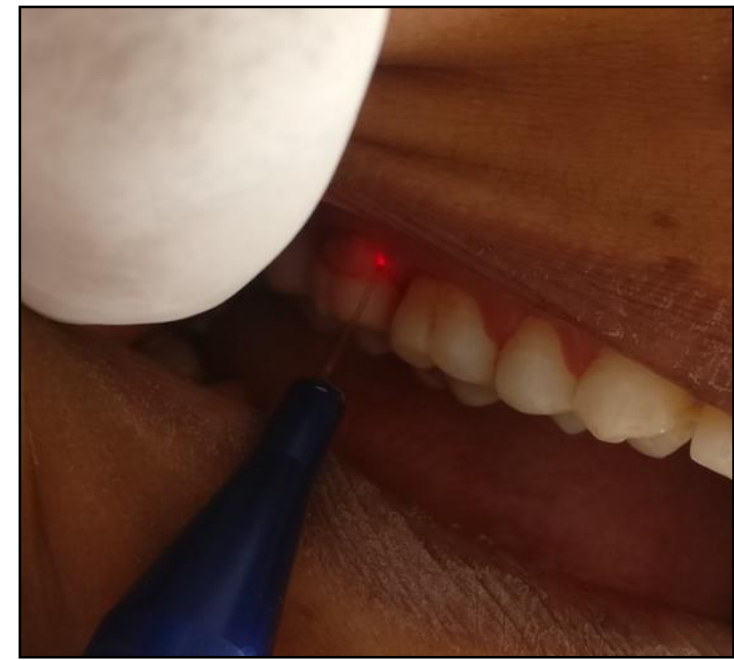

Fig-5c: Laser Assisted Periodontal Therapy (LAPT)

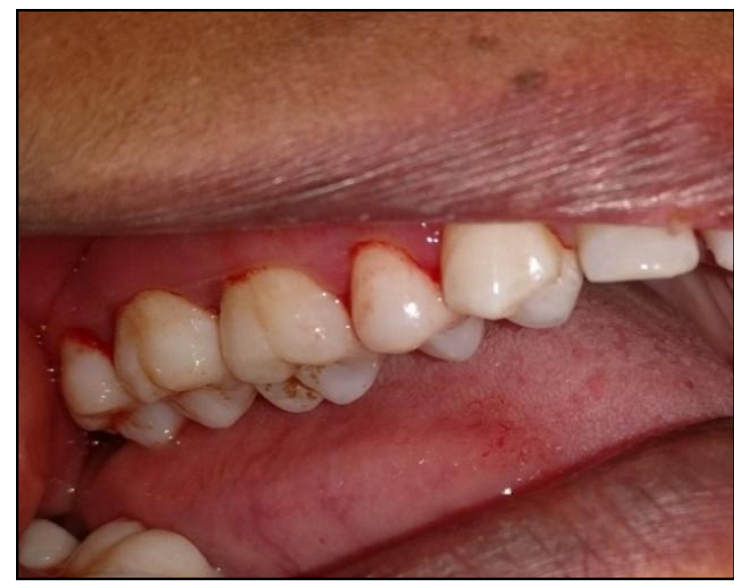

Fig-5d: Immediate Post Operative

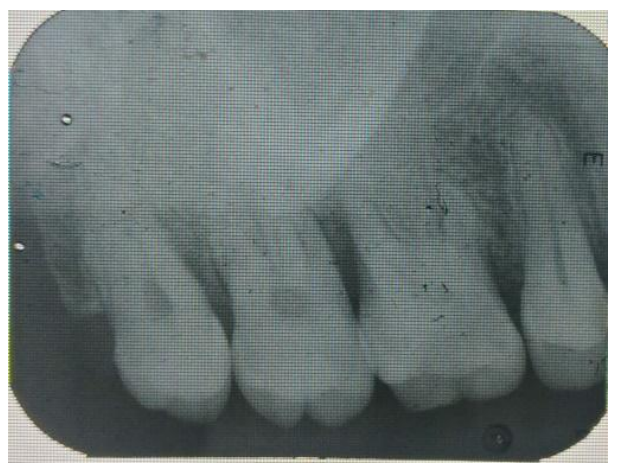

Fig-6a: 3 months follow up

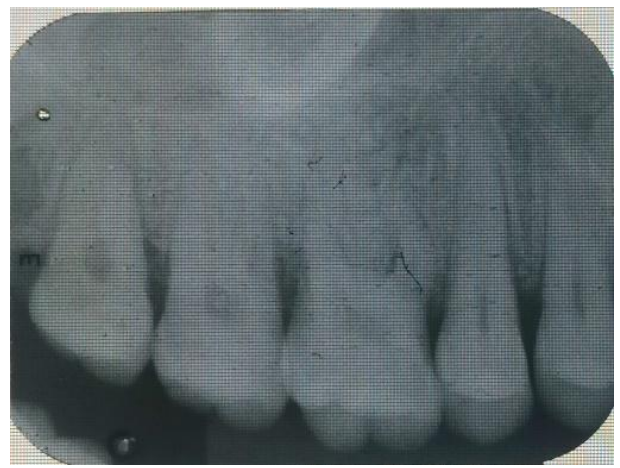

Fig-6b: 6 months follow up

\section{DISCUSSION}

The rationale for using laser in periodontal treatment is represented by a minimally invasive procedure for pocket elimination such as necrotic tissue removal, biofilm elimination, debridement, decontamination and biostimulation. The laser unit used in this case is a soft tissue diode laser (SUNNY) that produces laser wavelengths of $810 \mathrm{~nm}$ to $980 \mathrm{~nm}$. All diode wavelengths are absorbed primarily by tissue pigment (melanin) and hemoglobin. When compared with the conventional periodontal therapy, it has a greater patient acceptance.

Various studies had proved that LAPT allows clinicians to achieve predictable positive results including three-dimensional regeneration of bone and initiate regeneration of the connective tissue attachment [11-14]. Therefore, LAPT was considered as an adjunctive tool.

However, there is no evidence in the literature to evaluate the use of LASER in monostotic fibrous dysplasia patients with periodontitis.

\section{CONCLUSION}

LASER has an advantageous role to play in the treatment of periodontitis especially in patients with various dysplastic diseases of the bone such as fibrous dysplasia. The contribution of LAPT to the clinical result is good and may serve as an alternative option. However, it is imperative to perform a mechanical biofilm removal (SRP) prior to application of LASER in order to achieve optimum results.

\section{REFERENCES}

1. Lichtenstein, L. (1938). Polyostotic fibrous dysplasia. Archives of Surgery, 36(5), 874-898.

2. Liechtenstein, L., \& Jaffee, H. L. (1942). Fibrous dysplasia of bone: conditions affecting one, several or many bones, graver cases of which may present abnormal pigmentation of skin, premature sexual development, hyperthyroidism, and still other extra-skeletal abnormalities. Arch Patol, 33, 777-816.

3. Weinstein, L. S., Chen, M., \& Liu, J. (2002). Gs $\alpha$ mutations and imprinting defects in human disease. Annals of the New York Academy of Sciences, 968(1), 173-197.

4. DiCaprio, M. R., \& Enneking, W. F. (2005). Fibrous dysplasia: pathophysiology, evaluation, and treatment. JBJS, 87(8), 1848-1864.

5. Newman, M. G., Carranza, F. A., Takei, H., \& Klokkevold, P. R. (2006). Carranzas clinical Periodontology. 10th ed. Elsevier health sciences.

6. Gregg, R. H., \& McCarthy, D. (2001). Laser periodontal therapy. Dentistry today, 20(10), 7481. 
7. Gregg, R. H., \& McCarthy, D. (2002). Laser periodontal therapy for bone regeneration. Dentistry today, 21(5), 54-59.

8. Cobb, C. M., Low, S. B., \& Coluzzi, D. J. (2010). Lasers and the treatment of chronic periodontitis. Dental Clinics, 54(1), 35-53.

9. Moritz, A., Schoop, U., Goharkhay, K., Schauer, P., Doertbudak, O., Wernisch, J., \& Sperr, W. (1998). Treatment of periodontal pockets with a diode laser. Lasers in Surgery and Medicine: The Official Journal of the American Society for Laser Medicine and Surgery, 22(5), 302-311.

10. Kreisler, M., Al Haj, H., \& d'Hoedt, B. (2005). Clinical efficacy of semiconductor laser application as an adjunct to conventional scaling and root planing. Lasers in Surgery and Medicine: The Official Journal of the American Society for Laser Medicine and Surgery, 37(5), 350-355.
11. Sagar, K., Kaur, A., Patel, P., Kumar, V., Narang, S., \& Ranga, P. (2015). Diode laser as an established tool in periodontics-a review. Am J Oral Med Radiol, 2(2), 54-60.

12. Yukna, R. A., Carr, R. L., \& Evans, G. H. (2007). Histologic evaluation of an $\mathrm{Nd}$ : YAG laserassisted new attachment procedure in humans. International Journal of Periodontics \& Restorative Dentistry, 27(6):577-587.

13. Martin, I. S., \& Kim, M. D. (2014). A prospective 9-month human clinical evaluation of LaserAssisted New Attachment Procedure (LANAP) therapy. Periodontics, 34, 21-27.

14. McAllister, J. (2009). A high-tech approach to managing periodontal disease. Compendium of continuing education in dentistry (Jamesburg, NJ: 1995), 30(4), 228. 